\section{ISEP XIV}

\author{
Correspondence \\ T. Cavalier-Smith \\ tom.cavalier-smith@zoo.ox.ac.uk
}

\section{The excavate protozoan phyla Metamonada Grassé emend. (Anaeromonadea, Parabasalia, Carpediemonas, Eopharyngia) and Loukozoa emend. (Jakobea, Malawimonas): their evolutionary affinities and new higher taxa}

\author{
T. Cavalier-Smith \\ Department of Zoology, University of Oxford, South Parks Road, Oxford OX1 3PS, UK
}

It is argued here that the anaerobic protozoan zooflagellate Parabasalia, Carpediemonas and Eopharyngia (diplomonads, enteromonads, retortamonads) constitute a holophyletic group, for which the existing name Trichozoa is adopted as a new subphylum. Ancestrally, Trichozoa probably had hydrogenosomes, stacked Golgi dictyosomes, three anterior centrioles and one posterior centriole: the typical tetrakont pattern. It is also argued that the closest relatives of Trichozoa are Anaeromonada (Trimastix, oxymonads), and the two groups are classified as subphyla of a revised phylum Metamonada. Returning Parabasalia and Anaeromonadea to Metamonada, as in Grassé's original classification, simplifies classification of the kingdom Protozoa by reducing the number of phyla within infrakingdom Excavata from five to four. Percolozoa (Heterolobosea plus Percolatea classis nov.) and Metamonada are probably both ancestrally quadriciliate with a kinetid of four centrioles attached to the nucleus; the few biciliates among them are probably secondarily derived. Metamonada ancestrally probably had two divergent centriole pairs, whereas, in Percolozoa, all four centrioles are parallel. It is suggested that Discicristata (Percolozoa, Euglenozoa) are holophyletic, ancestrally with two parallel centrioles. In the phylum Loukozoa, Malawimonadea classis nov. is established for Malawimonas (with a new family and order also) and Diphyllatea classis nov., for Diphylleida (Diphylleia, Collodictyon), is transferred back to Apusozoa. A new class, order and family are established for the anaerobic, biciliate, tricentriolar Carpediemonas, transferring it from Loukozoa to Trichozoa because of its triply flanged cilia; like Retortamonas, it may be secondarily biciliate - its unique combination of putative hydrogenosomes and flanged cilia agree with molecular evidence that Carpediemonas is sister to Eopharyngia, diverging before their ancestor lost hydrogenosomes and acquired a cytopharynx. Removal of anaeromonads and Carpediemonas makes Loukozoa more homogeneous, being basically biciliate, aerobic and free-living, in contrast to Metamonada. A new taxon-rich rRNA tree supports holophyly of Discicristata and Trichozoa strongly, holophyly of Metamonada and Excavata and paraphyly of Loukozoa weakly. Mitochondria were probably transformed into hydrogenosomes independently in the ancestors of lyromonad Percolozoa and Metamonada and further reduced in the ancestral eopharyngian. Evidence is briefly discussed that Metamonada and all other excavates share a photosynthetic ancestry with Euglenozoa and are secondarily non-photosynthetic, as predicted by the cabozoan hypothesis for a single secondary symbiogenetic acquisition of green algal plastids by the last common ancestor of Euglenozoa and Cercozoa. Excavata plus core Rhizaria (Cercozoa, Retaria) probably form an ancestrally photophagotrophic clade. The origin from a benthic loukozoan ancestor of the characteristic cellular features of Percolozoa and Euglenozoa through divergent adaptations for feeding on or close to surfaces is also discussed.

This paper was presented at the XIVth meeting of the International Society for Evolutionary Protistology in Vancouver, Canada, 19-24 June 2002. Abbreviation: GPI, glucose-phosphate isomerase. 


\section{INTRODUCTION}

Over the past quarter-century, classification of the kingdom Protozoa has been undergoing successive improvements to make it phylogenetically sounder. The initial impetus was the dramatic diversity in cell structure revealed by high-resolution electron microscopy. More recently, the application of molecular biology has yielded a host of new characters, both molecular sequences and discrete features of gene organization or biochemical properties, that can be treated cladistically. The most recent phylogenetic classification of Protozoa (Cavalier-Smith, 2002b) placed particular emphasis on the organization of the microtubular cytoskeleton and simplified earlier proposals (Cavalier-Smith, 1993; Corliss, 1985, 1994; Patterson, 1999) by recognizing only 13 protozoan phyla grouped into two subkingdoms (Gymnomyxa and Corticata), each comprising two infrakingdoms (Sarcomastigota, Rhizaria and Excavata, Alveolata, respectively).

The present paper continues this simplification by grouping two excavate phyla (Parabasalia, Metamonada) into a new ancestrally anaerobic subphylum, Trichozoa, into which the anaerobic biciliate Carpediemonas is transferred from the excavate phylum Loukozoa. Anaeromonadea (Trimastix, Oxymonadida) are also removed from Loukozoa, making it much more homogeneous, and grouped with Trichozoa as a revised phylum Metamonada. Parabasalia and Eopharyngia are reduced in rank to superclass.

I shall discuss the phylogenetic evidence underlying these changes - in particular, evidence that Parabasalia and Eopharyngia/Carpediemonas are sisters, which is quite strong despite their substantial ultrastructural differences (Farmer, 1993), and argue that Trichozoa is the most appropriate existing name for a taxon embracing them all. I also discuss the phylogenetic evidence for a derived position within the Excavata of Metamonada, suggesting that they evolved from a malawimonad-like ancestor by ciliary multiplication and conversion of mitochondria into hydrogenosomes. I discuss the internal phylogeny of Metamonada and Loukozoa, their relationship to each other and other excavates and the probable origin of Euglenozoa and Percolozoa from jakobid-like Loukozoa. Finally, I argue that Excavata may have been ancestrally photosynthetic and sisters to a clade comprising Cercozoa and Retaria, recently grouped with Heliozoa and Apusozoa as the Rhizaria (Cavalier-Smith, 2002b).

To help explain the reasons for the taxonomic changes made here, I first need to outline past views on the Metamonada.

\section{Changing views of the Metamonada}

Ciliary number has always been an important practical feature of flagellate classification, even though it has long been known that numbers can readily increase and decrease in evolution and therefore are too phylogenetically unstable to be used on their own to define monophyletic groups.
Diesing $(1865,1866)$ called flagellates with six or more flagella Polymastiga. Many variants on this name arose, e.g. Polymastigina Bütschli 1884, Polymastigida Blochmann, and the vernacular term polymastigote was subsequently used and various subgroups segregated under a variety of other names, e.g. Tetramitidae for those with four cilia, from the polymastigotes, Octomitidae, Trichomonadida (Kirby, 1947) and Hypermastigida Grassi 1917. The criteria for inclusion or exclusion from the polymastigotes fluctuated: at different times, those with only two or three or four cilia or fewer than eight were included or excluded. In the leading mid-twentieth century synthesis, Grassé (1952) referred to most of the zooflagellates with four or more cilia as Metamonadina or Axostylaria [almost equivalent to the earlier Centrosomea of Chatton $(1925,1937)]$. The phylum Metamonada as revised here is identical to Grassé's Metamonadina except for the inclusion of diplomonads and Carpediemonas. Grassés Metamonadina excluded Tetramitus, which he correctly argued were related to vahlkampfiid amoebae, later grouped with similar discicristate amoeboflagellates and acrasid 'slime moulds' as the class Heterolobosea (Page \& Blanton, 1985), and subsequently grouped with Percomonadida, Pseudociliatida and Lyromonadida in the ancestrally discicristate phylum Percolozoa (Cavalier-Smith, 1993a, b, 2000). For a few decades, Grassé's Metamonadina were widely accepted (Honigberg et al., 1964, as order Metamonadina). However, following the discovery of radical differences in detailed body plan among them by electron microscopy, an era of oversplitting ensued. Honigberg (1973) created Parabasalia, initially a superorder, for trichomonads and hypermastigotes, which constituted the core of Grassés concept of Metamonadina, but the higher classification of zooflagellates remained rather confused and non-phylogenetic (Levine et al., 1980).

Attempting to rectify this, I raised Parabasalia in rank to phylum (Cavalier-Smith, 1981), because of their unique exonuclear mitosis, stacked parabasal Golgi and associated parabasal filament, hydrogenosomes and distinctive costa and axostyle, and established a phylum Metamonada for the rest of Grassé's Metamonadina plus diplomonads, a distinction adopted by Sleigh \& Patterson (1984) and many others, e.g. Brugerolle \& Müller (2000). Patterson (1988) used Metamonadida more narrowly for retortamonads and diplomonads and enteromonads, a grouping later called Eopharyngia (Cavalier-Smith, 1993a) or simply Metamonada (Cavalier-Smith, 1999). Initially, 18S rRNA trees appeared to confirm the deep divergence of diplomonads and Parabasalia by placing them at the root of the eukaryotic tree (Leipe et al., 1993; Cavalier-Smith, 1993a). For some years, I argued that parabasalian hydrogenosomes had evolved from mitochondria (Cavalier-Smith, 1987b), which is now thoroughly established (Dyall \& Johnson, 2000; van der Giezen et al., 2002), but thought that Metamonada might be primitively amitochondrial (Cavalier-Smith, 1983, 1987a) and therefore that the two groups were not a clade. 
However, two things dramatically changed this interpretation. One was the discovery of relics of a mitochondrial ancestry in the diplomonads Giardia (Roger et al., 1998; Morrison et al., 2001; Tachezy et al., 2001) and Spironucleus (Horner \& Embley, 2001). Secondly, the idea that rRNA is far from being a molecular clock (Cavalier-Smith, 1980) and that molecular trees with greatly unequal branches (Felsenstein, 1978) and other systematic biases can give a positively misleading tree have been used to argue that rooting the eukaryotic $18 \mathrm{~S}$ rRNA tree places the root artefactually between the very long-branch diplomonads and Parabasalia (Philippe \& Adoutte, 1996, 1998; Embley \& Hirt, 1998). Recently, study of a derived fusion between the dihydrofolate reductase and thymidylate synthetase genes (Philippe et al., 2000) and a complementary double fusion between three pyrimidine biosynthesis genes indicates that the root of the eukaryote tree is probably between the aerobic opisthokonts (animals, Choanozoa, fungi) plus the Amoebozoa (collectively called unikonts: Stechmann \& Cavalier-Smith, 2003a) and the aerobic common ancestor of bikonts (all other eukaryotes, namely Rhizaria, Excavata, chromalveolates and Plantae) (Stechmann \& CavalierSmith, 2002, 2003b). Concatenated mitochondrial protein trees (Lang et al., 2002) and a paralogue-rooted Hsp90 tree (Stechmann \& Cavalier-Smith, 2003a) indicate the same position for the root. Thus, there is no sound reason for rooting the tree between diplomonads and Parabasalia. Almost certainly, both groups had a common aerobic ancestor with mitochondria (Roger, 1999).

If the rRNA tree is not rooted between them, then Parabasalia and diplomonads are usually sisters with very strong bootstrap support (Cavalier-Smith, 2000, 2002b; Cavalier-Smith \& Chao, 2003b; Dacks et al., 2001), as they are on a concatenated protein tree (Baldauf et al., 2000) and more weakly on some single-gene protein trees (Embley \& Hirt, 1998; Dacks \& Roger, 1999). Furthermore, retortamonads robustly group with diplomonads (Silberman et al., 2002), so the taxon Eopharyngia Cavalier-Smith (1993), comprising diplomonads, enteromonads (morphologically quite similar to half a diplomonad cell and often included within them even though they are not double) and retortamonads only, is almost certainly holophyletic. Trimastix, which was treated by Grassé (1952) as a trichomonad, but is ultrastructurally distinctly different (Brugerolle \& Patterson, 1997; O’Kelly et al., 1999; Simpson et al., 2000), groups with oxymonads (Dacks et al., 2001; Moriya et al., 2003); this assemblage is now treated as a class Anaeromonadea (Cavalier-Smith, 2002b). Oxymonadida were also originally included in Metamonadina (superorder Grassé 1952; phylum Cavalier-Smith 1981) and phylum Metamonada (Sleigh \& Paterson, 1984; Cavalier-Smith, 1987a, 1989, 1993a). An origin of oxymonads from a Trimastix-like ancestor by the loss of the feeding groove after they became gut symbionts, for the same reasons but independently of the cytoskeletal internalization postulated earlier for Parabasalia (Cavalier-Smith, 1992), is cytologically supported by ciliary root homologies (Simpson et al., 2002b). Anaeromonadea have been variously classified: initially with Parabasalia as phylum Trichozoa (CavalierSmith, 1997), later with Jakobea in the phylum Loukozoa (Cavalier-Smith, 1999).

\section{METHODS}

Cell cultures and methods. The marine Jakoba libera (Ruinen) Patterson 1990 culture was kindly donated by R. J. Gast and D. A. Caron (Woods Hole Oceanographic Institution) (WHOI DB9, isolated by Delma Bratvold from Upper Chesapeake Bay, $0.5 \mathrm{~m}$ deep). Reclinomonas sp. was a Russian isolate from a freshwater pond at Yaraslavl, kindly donated as a uniprotist culture by A. P. Mylnikov under the name Histiona campanula, and has now been placed in the American Type Culture Collection (ATCC 50633). Unlike in H. campanula (reclassified as Reclinomonas campanula by Flavin \& Nerad, 1993), the lorica of this strain is not attached at an angle to the stalk; however, T. Nerad (personal communication) does not regard it as Reclinomonas americana because of the high density and greater length of its lorica spines. The J. libera sequence of Simpson et al. (2002a) (strain not given in their paper, but was ATCC 50241, isolated by $\mathrm{T}$. Nerad from water overlying sediment at No name canyon, 1912-1918 m deep; B. F. Lang, personal communication) differs by 47 nucleotides from ours and their $R$. americana sequence differs by 12-24 nucleotides (it has 12 ambiguities) from our Reclinomonas sp. Thus, both their strains may represent different 'species' from ours, consistent with the morphological differences noted by T. Nerad between the two Reclinomonas strains and the presence of a Group 1 intron only in our strain. The large difference between the two J. libera strains (one from surface water, the other from the deep ocean) suggests that J. libera is not a single species but a species complex of at least two quite distantly related cryptic species.

DNA isolation, purification, 18S rRNA gene amplification by PCR, direct sequencing, editing and addition to multiple alignments were done as described previously (Cavalier-Smith \& Chao, 1996). The new sequences were aligned manually with our aligned database of over 450 diverse eukaryote sequences.

\section{RESULTS}

\section{A new rRNA analysis and classification for excavates}

It might be thought from published $18 \mathrm{~S}$ rRNA trees (Dacks et al., 2001; Silberman et al., 2002) that Anaeromonadea are less closely related to Trichozoa than are Percolozoa, which, on 18S rRNA trees, are often a sister to Parabasalia plus diplomonads, but, as this has only moderate (CavalierSmith, 2000, 2002b) or low (Dacks et al., 2001) bootstrap support and Trichozoa are such a long branch, their placement within discicristates is probably artefactual.

Fig. 1 is a new analysis with representatives from all major excavate taxa; it includes our own jakobid sequences (in bold), included in an earlier illustrative tree (CavalierSmith, 2000) but not previously formally published, as well as those for different strains from Simpson et al. (2002a). As retortamonads have much shorter branches than diplomonads, they alone are included in Fig. 1 to represent Eopharyngia. In Fig. 1, Carpediemonas is weakly sister to 


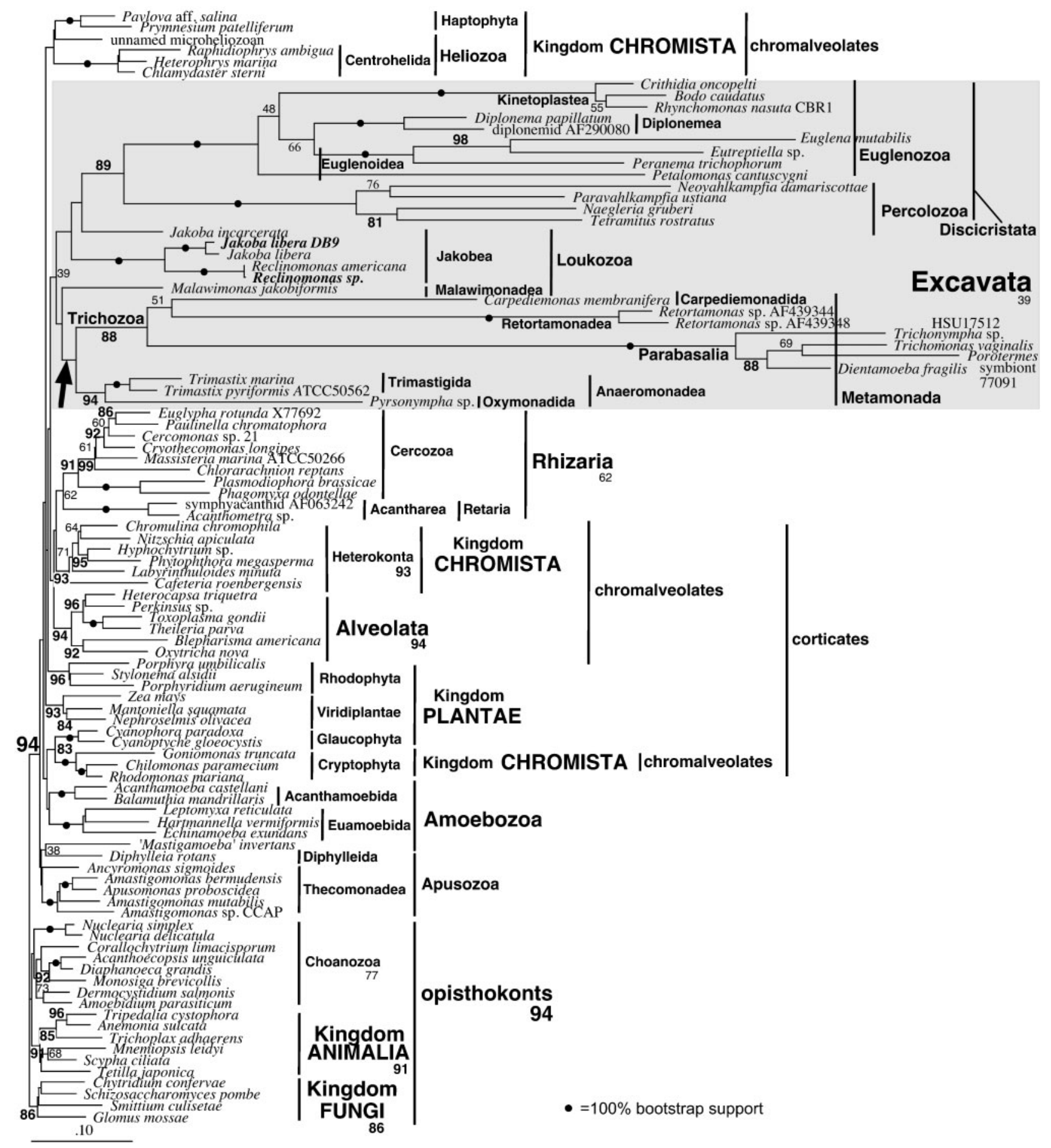

Fig. 1. Kimura's two-parameter distance tree of $18 \mathrm{~S}$ rRNA sequences from 98 representatives of all major eukaryote groups using 1338 positions (alignment available on request) and allowing for intersite substitution rate variation $(\Gamma+\mathrm{I}$ model: $\mathrm{a}=0 \cdot 8$, $i=0 \cdot 18$ ). Figures are bootstrap percentages (bold if $80 \%$ or more); except within excavates, those below $60 \%$ are not shown. Four values are omitted within excavates because, in the compatible groups consensus tree from the bootstrap analysis, Trichozoa moved to be sister to Discicristata with $63 \%$ support (J. incarcerata was sister to this clade with $31 \%$ support, Malawimonas was sister to Anaeromonadea with $57 \%$ support). All sequences outside the four derived kingdoms (animals, fungi, plants, chromists) belong to the basal kingdom Protozoa. Excavates are highlighted in grey. The putative timing of the origin of tetrakonty in the ancestral metamonad and of its hydrogenosomes from mitochondria is shown by an arrow. 
retortamonads, consistent with the ultrastructurally based suggestion of Simpson \& Patterson (2001) and the molecular findings of Simpson et al. (2002a), while the retortamonad/Carpediemonas clade is very robustly sister to Parabasalia. However, in marked contrast to many published trees, Fig. 1 shows Anaeromonadea as sisters to the retortamonad/Carpediemonas/Parabasalia clade, albeit with very weak bootstrap support. This overall clade corresponds precisely with the Metamonada as revised in the new excavate classification summarized in Table 1. In Fig. 1, Metamonada is in turn weakly sister to Malawimonas in a derived position within the aerobic excavates. Several other gamma-corrected distance trees with different taxon samples and/or substitution models (not shown) also show the Parabasalia/Eopharyngia clade grouping weakly with Anaeromonada and thus a holophyletic Metamonada.

Discicristates are robustly holophyletic and branch within a paraphyletic Jakobea, which is consistent with published rRNA or protein trees (Archibald et al., 2002; Edgcomb et al., 2001; Simpson et al., 2002a) and with my suggestion that the grouping of Percolozoa and Trichozoa on most published rRNA trees is a long-branch artefact (eliminated here by using retortamonads rather than diplomonads to represent Eopharyngia).

\section{DISCUSSION}

\section{Inclusion of Parabasalia, Trepomonadea and Carpediemonas in the Metamonada}

Metamonada in the present sense is much closer to the intention of Grassé (1952) and in circumscription than the previous usage that excluded Parabasalia (Cavalier-Smith, 1981, 1987a, 1989, 1993a, 1998; Sleigh \& Patterson, 1984; Brugerolle \& Müller, 2000), as the parabasalian exonuclear spindle was an important feature of his definition of the group, together with the presence of an axostyle. However, the exonuclear spindle is clearly a derived character for Parabasalia alone; as Grassé's metamonads included oxymonads and retortamonads that were known exceptions, the addition of trepomonads also does not greatly change the basic concept. Metamonada now differs only by definitely including Trepomonadea (diplomonads and enteromonads), which Grassé (1952) excluded because they had no axostyle despite including them in the broader group Centrosomea, and the free-living anaerobic biciliate Carpediemonas, which was unknown to him. The longpresumed relationship between retortamonads and Trepomonadea is decisively confirmed by $18 \mathrm{~S}$ rRNA trees, which suggest that they may be derived from within Trepomonadea, possibly being closer to Giardiida than Distomatida (Silberman et al., 2002). It also differs from Grassé's superorder Metamonadina in its higher rank, which is necessary to give superclass status to Parabasalia and Eopharyngia. Grassé's 1952 alternative name Axostylaria would have been unsuitable for the expanded group, as the added taxa lack axostyles. Furthermore, electron microscopy has shown that oxymonad axostyles in the form of a crystalline array of three-dimensionally cross-linked microtubules are very different from the hollow axostyles of Parabasalia, which consist of a single curved, twodimensional sheet of microtubules (Brugerolle \& Müller, 2000). There is no reason to think that these two structures are homologous. Centrosomea would be too non-specific a name, as most eukaryotes have centrosomes. As metaimplies 'later than', 'beyond' or 'of a higher order', Metamonada better expresses the probably derived nature of the group (see discussion below) than does Archezoa, the term I have been using latterly to designate Parabasalia and Metamonada (Cavalier-Smith, 1998, 2002b), but therefore now abandon as a taxon.

The reason for originally ranking Metamonadina and Parabasalia as phyla (Cavalier-Smith, 1981) was not that the differences between them were too great to allow them to be put in one phylum, but because of scepticism that they were sisters. This scepticism was increased after I concluded that parabasalian hydrogenosomes evolved from mitochondria (Cavalier-Smith, 1987b) (now proved correct) but still thought that Eopharyngia never had mitochondria (now proved false). Now that there are no obstacles to their being considered sisters, the rank of superphylum seems too high for Metamonada.

\section{Nomenclatural comments}

There is always a problem when improving classification by grouping or splitting taxa over whether to invent entirely new names or modify the application of existing ones; either approach will meet opposition during the transitional period when new proposals are being evaluated by the scientific community, as the desire for stability for which we all yearn is in fundamental conflict with the need for classification to evolve so as to reflect scientific advances in understanding. The present paper makes significant changes in circumscription to four major taxa: Metamonada, Trichozoa, Loukozoa and Apusozoa. This may cause slight temporary confusion, but will allow greater clarity in the long run.

The phylum Trichozoa was invented to embrace Trimastix and Parabasalia (Cavalier-Smith, 1997) because I considered that they had a common ancestor with a quadriciliate kinetid, hydrogenosomes and Golgi dictyosomes. I still consider this to be the case, but now think that Eopharyngia and Carpediemonas also were descended from this same ancestor by the loss of hydrogenosomes and dictyosomes (Eopharyngia) or of the fourth centriole and two cilia (Carpediemonas), making the original Trichozoa paraphyletic. In preparing this paper, I considered simply adding these taxa to the Trichozoa to make the phylum holophyletic. However, I decided that it was preferable to use Grassés older and more widely used name for this expanded holophyletic assemblage and to modify the circumscription of Trichozoa (now reduced in rank to subphylum) not only by adding these taxa, but also by 
Table 1. Classification of infrakingdom Excavata, its four phyla, 14 classes and 26 orders

\section{Taxon}

Superphylum 1. Eozoa Cavalier-Smith 1996/7 emend. 1999 stat. nov.

Phylum 1. Loukozoa* Cavalier-Smith 1999 emend.

Class 1. Jakobea† Cavalier-Smith 1999

Order Jakobida Cavalier-Smith 1993. Families Histionidae Flavin \& Nerad 1993 (Reclinomonas, Histiona), Jakobidae Patterson 1990 (Jakoba)

Class 2. Malawimonadea classis nov.

Order Malawimonadida ord. nov. (Malawimonas)

Phylum 2. Metamonada Grassé 1952 stat. nov. emend.

Subphylum 1. Anaeromonada Cavalier-Smith 1996/7

Class Anaeromonadea Cavalier-Smith 1996/7 emend. 1999

Order 1. Trimastigida ord. nov. (Trimastix)

Order 2. Oxymonadida Grassé 1952 emend. auct. (e.g. Pyrsonympha, Dinenympha)

Subphylum 2. Trichozoa Cavalier-Smith 1996/7 stat. nov. emend.

Superclass 1. Parabasalia Honigberg 1973 stat. nov.

Class 1. Trichomonadea Kirby 1947 stat. nov. Margulis 1974 emend.

Order 1. Trichomonadida Kirby 1947 (e.g. Trichomonas, Calonympha)

Order 2. Lophomonadida Light 1927 (e.g. Lophomonas, Microjoenia)

Order 3. Spirotrichonymphida Grassé 1952 (e.g. Spirotrichonympha, Holomastigoides)

Class 2. Trichonymphea classis nov.

Order Trichonymphida Poche 1913 (e.g. Trichonympha)

Superclass 2. Carpediemonadia superclassis nov.

Class Carpediemonadea classis nov.

Order Carpediemonadida ord. nov. (Carpediemonas)

Superclass 3. Eopharyngia Cavalier-Smith 1993 stat. nov.

Class 1. Trepomonadea Cavalier-Smith 1993

Subclass 1. Diplozoa Dangeard 1910 stat. nov. Cavalier-Smith 1996 (diplomonads)

Order 1. Distomatida Klebs 1892 (Trepomonas, Hexamita, Spironucleus)

Order 2. Giardiida Cavalier-Smith 1996 (Giardia, Octomitus)

Subclass 2. Enteromonadia (enteromonads) Cavalier-Smith 1996

Order Enteromonadida Brugerolle 1975 stat. nov. Cavalier-Smith 1993 (Enteromonas)

Class 2. Retortamonadea Cavalier-Smith 1993

Order Retortamonadida Grassé 1952 (e.g. Retortamonas, Chilomastix)

Superphylum 2. Discicristata Cavalier-Smith 1993

Phylum 1. Percolozoa Cavalier-Smith 1991

Class 1. Heterolobosea Page \& Blanton 1985

Order 1. Schizopyrenida Singh 1952 (e.g. Naegleria, Tetramitus, Vahlkampfia)

Order 2. Acrasida Shröter 1886 emend. Page \& Blanton 1985 (e.g. Acrasis)

Order 3. Lyromonadida Cavalier-Smith 1993 (Lyromonas, Psalteriomonas)

Class 2. Percolatea classis nov.

Order 1. Percolomonadida Cavalier-Smith 1993 (Percolomonas)

Order 2. Pseudociliatida Corliss \& Lipscomb 1982 (Stephanopogon)

Phylum 2. Euglenozoa Cavalier-Smith 1981

Subphylum 1. Plicostoma Cavalier-Smith 1998

Class 1. Euglenoidea Bütschli 1884

Order 1. Petalomonadida Cavalier-Smith 1993 (bacteria-eaters, e.g. Petalomonas, Calycimonas)

Order 2. Peranemida Bütschli 1884 (eukaryote-eaters with complex vane/rod ingestion apparatus, e.g. Peranema, Entosiphon)

Order 3. Rhabdomonadida Leedale 1967 emend. (saprotrophs, e.g. Menoidium, Rhabdomonas, Distigma)

Order 4. Euglenida Bütschli 1884 (plastid-bearing, mostly photosynthetic, e.g. Euglena, Astasia, Eutreptia, Phacus, Trachelomonas)

Class 2. Diplonemea Cavalier-Smith 1993

Order Diplonemida Cavalier-Smith 1993 (Diplonema, Rhynchopus)

Subphylum 2. Saccostoma Cavalier-Smith 1998

Class 1. Kinetoplastea Honigberg 1963 stat. nov. Margulis 1974

Order 1. Bodonida* Hollande 1952 (e.g. Bodo, Rhynchomonas, Cryptobia, Dimastigella, Ichthyobodo, Trypanoplasma)

Order 2. Trypanosomatida Kent 1880 stat. nov. Hollande 1952 (e.g. Trypanosoma, Crithidia, Leishmania, Herpetomonas) 
Table 1. cont.

\begin{tabular}{|l|}
\hline Taxon \\
\hline Class 2. Postgaardea Cavalier-Smith 1998 \\
Order Postgaardida ord. nov. Diagnosis: mitochondria without kinetoplast or cristae (Postgaardi, Calkinsia) \\
Protozoa incertae sedis \\
Phylum Apusozoa Cavalier-Smith 1996/7 stat nov. 2003 emend. \\
Class 1. Diphyllatea classis nov. \\
Order Diphylleida Cavalier-Smith 1993 (Diphylleia, Collodictyon) \\
Class 2. Thecomonadea Cavalier-Smith 1993 stat. nov. 1995 \\
Order 1. Apusomonadida Karpov \& Mylnikov 1989 (Amastigomonas, Apusomonas) \\
Order 2. Ancyromonadida Cavalier-Smith 1998 (Ancyromonas) \\
Order 3. Hemimastigida Foissner, Blatterer \& Foissner 1988 (e.g. Hemimastix, Spironema) \\
\hline
\end{tabular}

${ }^{\star}$ Probably paraphyletic.

$\dagger$ Once also included Discocelida (Cavalier-Smith, 1997), but molecular data are needed to determine whether this is correct.

excluding Anaeromonadea, allowing the useful retention of both names for two nested clades while avoiding the creation of new ones for either revised concept.

Excluding the fundamentally quadriciliate and anaerobic Anaeromonadea from Loukozoa makes the latter much more homogeneous; it now comprises two ancestrally biciliate classes having ventral grooves with rims supported by microtubules and an associated dense band, but differing in how the floor of the groove is supported by diverging root microtubules and in whether the posterior ciliary vane is ventral or dorsal. The name Loukozoa (from Gr. loukos groove) is descriptively apposite for all members of the phylum as now circumscribed; it had become less so than originally (Cavalier-Smith, 1999) when the grooveless oxymonad gut symbionts were added because of their demonstrated relationship to Trimastix (Cavalier-Smith, 2002b).

\section{Tetrakonty}

The term tetrakonty (Cavalier-Smith, 1991) originally applied to the character of four associated centrioles bearing cilia, with usually one recurrent undulating cilium involved in feeding and usually three anterior cilia with an oar-like motion for propulsion. It was not intended as a synonym for the quadriciliate condition (Cavalier-Smith, 1992, p. 93), which has arisen more than once, notably also within green algae, being the predominant kinetid pattern in the subphylum Chlorophytina (Cavalier-Smith, 1998; Wolfe et al., 2002), but, as they have four similarly beating anterior cilia, kinetid organization is completely different, especially in prasinophytes where all centrioles are typically parallel, and they are quadriciliate but not tetrakont. The arrangement of three anterior (or one anterior and two anterolateral) and one posterior centriole characteristic of Metamonada has been remarked on for decades (Grassé, 1952; Farmer, 1993) and constitutes a shared derived character that defines the group. I originally assumed that Percolozoa, which have four parallel centrioles, had evolved from such an ancestor by centriolar reorientation and therefore included them loosely among the tetrakonts (Cavalier-Smith, 1991, 1992). I now think this was probably a mistake and favour restricting the term tetrakont to kinetids with at least one posterior centriole bearing a recurrent cilium. Only Metamonada are truly tetrakont in this sense. I previously argued that tetrakonty is a derived condition and that tetrakonts evolved from anisokont biciliate ancestors (Cavalier-Smith, 1987a, 1991, 2000, 2002b). It seems likely that Trichozoa evolved from metamonad ancestors with cruciately arranged centrioles, like Trimastix, and that Trimastix in turn evolved from a biciliate loukozoan similar to Malawimonas.

In principle, the postulated progression from uniciliate to biciliate to tetraciliate makes great cell-biological sense (Cavalier-Smith, 1982, 1987a, 1991, 1993a, 2000, 2002b), especially since the discovery of ciliary transformation (reviewed by Moestrup, 2000), but we also know that secondary reversion can occur and thus need to establish which groups are ancestrally uni-, bi- or quadriciliate.

For Percolozoa, at least some of the biciliate genera, e.g. Naegleria, are nested within the otherwise quadriciliate or non-ciliate Heterolobosea (now also including the lyromonads, which have either one or four quadriciliate kinetids). I suggest that the ancestral percolozoan had quadriciliate kinetids, most probably a single one. As all four centrioles are parallel in both percolozoan classes, their kinetid structure provides no evidence that they were ever truly tetrakont. As Loukozoa all have two divergent, obtusely angled centrioles, it is likely that the quadriciliate condition evolved independently in Metamonada and Percolozoa from such an ancestor by ciliary multiplication (Cavalier-Smith, 1993a). It is less likely that a group with fundamentally parallel centrioles would give rise to the tetrakont arrangement, which is one reason for questioning the common rRNA grouping of Trichozoa and Percolozoa (this probable artefact is not seen in Fig. 1, possibly because of the combination of large excavate taxon sampling, gamma 
correction and exclusion of the long-branch diplomonads). Also important are the detailed similarities in ciliary roots and ciliary vanes of Carpediemonas and other Trichozoa that have been critically discussed by Simpson \& Patterson $(1999,2001)$. Together, these strongly suggest that Carpediemonas is the closest known relative of Eopharyngia and Parabasalia, which is confirmed by molecular data (Simpson et al., 2002a; see also Fig. 1). Its trikont state of three centrioles is probably a relic of a tetrakont ancestry. These similarities also make the biciliate Malawimonas a much better model for the ancestor of Metamonada than the quadriciliate Collodictyon (now in Apusozoa rather than Loukozoa). The extra centrioles in Collodictyon are in the same position as the two younger centrioles normally made prior to cell division (Brugerolle et al., 2002), so its quadriciliate condition may have evolved simply by the accelerated development of cilia from them. The lateral cilia of Trimastix, probably the ancestral state for Metamonada, probably originated similarly but independently.

\section{Evidence that Trichozoa are holophyletic}

From the 18S rRNA tree (Silberman et al., 2002), we can now infer, as long suspected from their four centrioles, that the biciliate Retortamonas have almost certainly arisen from a quadriciliate ancestor by the suppression of growth of two cilia. If we also accept the reasonable inference that Caviomonas, the only trepomonadean with no anterior cilia, has lost them (Cavalier-Smith, 1992; Brugerolle \& Müller, 2000), it follows that the ancestral eopharyngian was quadriciliate and tetrakont. For Parabasalia also, the $18 \mathrm{~S}$ rRNA tree clearly confirms earlier deductions from morphology that the non-ciliated Dientamoeba arose by ciliary loss and that the ancestral parabasalian had several anterior cilia (probably three) and a recurrent cilium (Gerbod et al., 2001). Thus, the metamonad ancestor of both groups almost certainly had three anterior and one posterior cilium and was thus a true tetrakont.

If we are to use cladistic arguments from outgroups effectively to decide what is ancestral and what is derived, we need to know how the part of the tree under consideration is rooted. The profound morphological differences between bacteria and eukaryotes have made it very hard to use morphological cladistic arguments successfully to root the tree. However, an arguably derived gene fusion between the dihydrofolate reductase and thymidylate synthetase genes (Philippe et al., 2000; Stechmann \& Cavalier-Smith, 2002, 2003b) and a double fusion between three pyrimidine biosynthesis genes (Stechmann \& CavalierSmith, 2003b) have now together provided strong evidence that the root of the eukaryote tree lies between the opisthokonts (animals, Choanozoa and Fungi: CavalierSmith, 1987c) plus the Amoebozoa (collectively designated unikonts: Stechmann \& Cavalier-Smith, 2003a) and the bikonts (all other eukaryotes: Cavalier-Smith, 2002b). An important consequence of this new insight into the root of the eukaryote tree is that we can now root the bikont part by using unikonts as the outgroup and do not need to use bacteria, whose genes are so divergent that they often pull Trichozoa (the bikont group with the most rapidly evolving genes) artefactually to the base of the tree; that was almost certainly a problem with the rRNA tree of Silberman et al. (2002) and the protein tree of Bapteste et al. (2002). When rRNA trees (Cavalier-Smith, 2002b) or trees based simultaneously on several (Baldauf et al., 2000) or many (Bapteste et al., 2002) different proteins are rooted between unikonts and bikonts, Parabasalia and Eopharyngia are a derived branch within the bikonts (Fig. 1), as their complex tetrakonty has long suggested should be the case (CavalierSmith, 1982, 1987a, 1993a, 2002b). Furthermore, both rRNA (Cavalier-Smith, 2000, 2002b) and proteins (Baldauf et al., 2000) show them as sisters with strong bootstrap support (Fig. 1).

Given that the root of the eukaryotic tree does not lie within Trichozoa, the absence of hydrogenosomes and Golgi dictyosomes in trophic Eopharyngia is almost certainly the result of secondary losses and thus does not argue against their being sisters of Parabasalia. The apparent absence of a costa in Eopharyngia further exaggerates the difference from Parabasalia. However, the ultrastructural similarity of the costa to the C-fibre of Loukozoa led to the suggestion that the two are homologous (Simpson \& Patterson, 2001), which would require the ancestral parabasalian to have had a costa. Recent molecular trees for Parabasalia (Gerbod et al., 2001) confirm that the costa has probably been lost several times within Parabasalia and was present in the ancestral parabasalian. The exonuclear spindle of Parabasalia is a unique derived character that arose independently of similar but non-identical mitoses of dinoflagellates, and so their sisters must necessarily lack this character. As the microtubular cytoskeleton in Parabasalia is predominantly internal and the cell surface amoeboid, in contrast to the Eopharyngia, which have cortical microtubule bands like Loukozoa, these are derived states that probably arose after their ancestor became a gut parasite and was bathed in food from all sides; the loss of the feeding groove was a (non-inevitable) consequence of gut symbiosis (Cavalier-Smith, 1992). All these ultrastructural differences indicate that Parabasalia and Eopharyngia are deeply divergent from each other, but none of them suggests that either group is more closely related to a different outgroup than they are to each other. As the eopharyngian kinetid comprises two pairs of diverging centrioles, like the outgroup Trimastix, it is likely that this is the ancestral condition for Trichozoa and that the three parallel anterior centrioles of Parabasalia arose secondarily by simplifying the centriolar connectives in association with cytoskeletal modifications when their cell surface became more amoeboid.

Shared derived lateral gene transfers can provide powerful evidence for the validity of clades that is not directly affected by the long-branch problems that so often distort tree topology. Two such transfers clearly support the holophyly of Trichozoa. Parabasalia and Eopharyngia share versions of 
the glycolytic enzymes glucokinase and glucose-phosphate isomerase (GPI) that are otherwise known in eukaryotes only in green plants (Henze et al., 2001). Other eukaryotes use completely unrelated proteins to catalyse the same reactions. The only other eukaryote known to have a related 'glucokinase' gene (the enzyme has not been studied directly) is the tetraphyte alga Chlamydomonas reinhardtii. As the diplomonad versions of this gene, at least, are more closely related to those of cyanobacteria (Henze et al., 2001; $\mathrm{Wu}$ et al., 2001), the simplest interpretation is that it was acquired by the ancestral plant from the cyanobacterium that formed the ancestral plastid and persisted in the tetraphyte lineage, though other interpretations of the trees are possible.

The ancestor of the Trichozoa could have acquired the same glucokinase gene by lateral transfer, either independently from cyanobacteria or directly from a green alga. The latter is much more likely, as tetraphyte green algae are the very group that donated the green plastid to the ancestor of the euglenoids, the only excavate group currently with photosynthetic members (Cavalier-Smith, 1993a). According to the cabozoan theory, this lateral transfer of green algal plastids took place not within the euglenoids, as commonly assumed (Gibbs, 1978; Delwiche, 1999), but in the common ancestor of Euglenozoa and Cercozoa, the phylum containing chlorarachnean algae, which also have green chloroplasts of secondary symbiogenetic origin (probably also from a tetraphyte source: Cavalier-Smith, 1999, 2003). On this hypothesis, for which there are strong arguments based on considerations of parsimony in the evolution of protein targeting (Cavalier-Smith, 1999, 2003), all excavates must be derived from a photosynthetic common ancestor by plastid losses. If the phylogeny shown in Fig. 2 is correct, plastids would have been lost in the common ancestor of Percolozoa and separately in the ancestor of Metamonada/Malawimonadea and in jakobids in addition to losses within Euglenozoa. The basal phylogeny of Cercozoa is still uncertain (Cavalier-Smith \& Chao, 2003c), but the cabozoan hypothesis must assume at least four losses among them and a fifth in the ancestral rhizarian. If the excavate phylogeny of Fig. 1 is correct, at least nine plastid losses must be inferred within excavates, but, as molecular evidence independent of the cabozoan hypothesis (and arising since its proposal) suggests that the ancestral excavate may have been photosynthetic, these are no longer additional assumptions of the theory; indeed, this independent evidence goes some way to corroborate the theory. Fourteen plastid losses within the cabozoa is similar to the number of mitochondrial 'losses' (or, more properly, conversions to hydrogenosomes or mitosomes) that have occurred in eukaryotes and is therefore a rather weak disadvantage of the theory compared with the advantage of assuming a common origin for protein-targeting into the plastid of euglenoids and chlorarachneans (Cavalier-Smith, 2003). If we had a chlorarachnean chloroplast genome sequence, it might help us to decide whether or not the cabozoan theory is correct.
Relatives of the GPI gene are widely present in eukaryotes. However, those of diplomonads and Parabasalia are very different from all the others but branch robustly with each other as a strongly supported clade (Henze et al., 2001). Although the stem joining the clade is rather long, these sequences branch with those of flowering-plant chloroplasts and cyanobacteria rather than with the much more distant plant cytosolic genes that are related to those of Apicomplexa and more distantly to opisthokonts and kinetoplastids. Again, the simplest interpretation would be that the green-plant chloroplast versions were acquired from cyanobacteria and that the more divergent trichozoan versions were transferred laterally to them during secondary symbiogenesis in the cabozoan common ancestor. Although the long branches of the trichozoan versions of the hexokinase and GPI genes make it impossible to distinguish by tree topology between lateral transfer during such secondary symbiogenesis and direct lateral transfer from cyanobacteria, the precise evolutionary pathway is irrelevant to the argument that these shared genes provide direct evidence for the holophyly of Trichozoa, as they must have been acquired by lateral transfer by a common ancestor of Parabasalia and Eopharyngia. Strictly speaking, in the absence of data for anaeromonad GPI, we do not know whether the shared diplomonad/parabasalid GPI is really a synapomorphy for Trichozoa or for Metamonada; what it does mean is that the root of the tree does not lie within the Trichozoa, as incorrectly suggested by most $18 \mathrm{~S}$ rRNA trees rooted by bacterial sequences.

\section{The probably photosynthetic ancestry of excavates}

Similar considerations apply to the recent evidence that Trichozoa share a form of 6-phosphogluconate dehydrogenase (Gnd) that is highly divergent from all others in the living world. Although its origin is uncertain, it provides good evidence for their holophyly (Andersson \& Roger, 2002). This gene is of key significance for excavate phylogeny, as the presence in the percolozoan Naegleria of a version of this gene that is most closely related to that of plant and chromist chloroplasts (and more distantly to cyanobacteria) strongly indicates that the common ancestor of discicristates had a plastid. Whether this was the secondary symbiogenetic ancestor of the euglenoid chloroplast, as I contend (Cavalier-Smith, 2002c, 2003), or reflects an earlier primary origin of chloroplasts from cyanobacteria than usually supposed, as Andersson \& Roger (2002) tend to think, is irrelevant to the fact that it provides evidence that at least one of the two excavate superphyla was ancestrally photosynthetic. Both on the cabozoan theory (Cavalier-Smith, 1999) and on the theory of a primary origin of plastids before the divergence of Plantae and Excavata (Andersson \& Roger, 2002), all excavates must have had a photosynthetic common origin if excavates are holophyletic, as is highly probable [despite their lack of coherence on many single-gene trees (e.g. Archibald et al., 2002; Dacks et al., 2001; Edgcomb et al., 


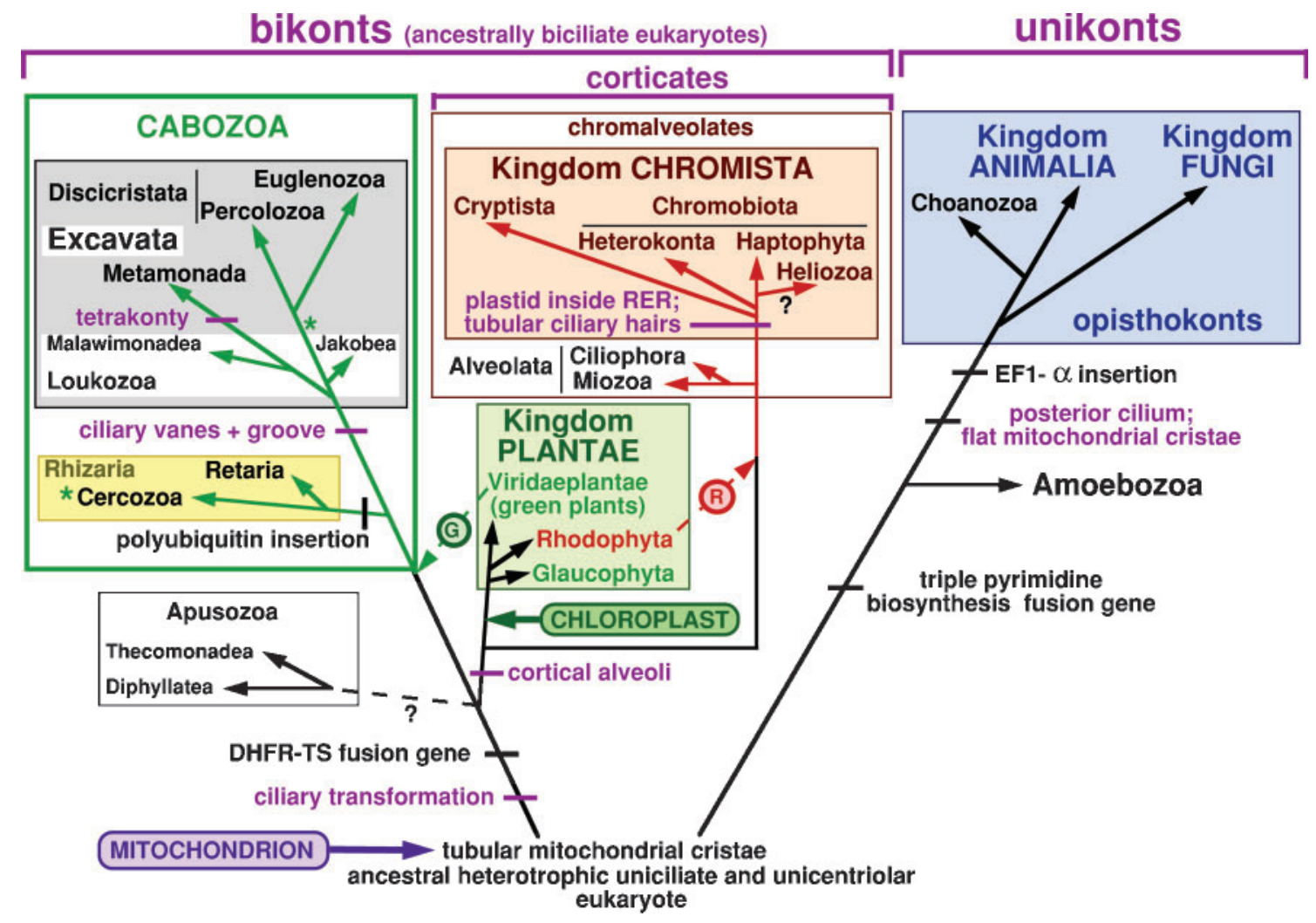

Fig. 2. Eukaryotic phylogenetic tree based on a synthesis of ultrastructural, cell-biological and molecular evidence, showing the four major symbiogenetic events and the derived position of the four excavate phyla. Taxa belonging to the basal kingdom Protozoa are in black, while the four derived kingdom names are coloured. The ancestral eukaryote is held to have been a phagotrophic, uniciliate and unicentriolar aerobic zooflagellate that arose from a neomuran bacterial ancestor by the simultaneous origin of the cytoskeleton, endomembrane system, nucleus and cilium, coupled with the overlapping symbiogenetic origin of mitochondria from an intracellular $\alpha$-proteobacterium (Cavalier-Smith, 2000, 2002a). It is reasonably certain that unikonts are ancestrally heterotrophic and that chloroplasts arose symbiogenetically in an early bikont. It is firmly established that chromalveolates are holophyletic, ancestrally photophagotrophic and evolved by the single enslavement of a red alga $(R)$ by a bikont host to form a eukaryote-eukaryote chimaera. There are almost equally strong protein-targeting arguments for the single secondary origin of the cabozoan chloroplast $(G)$ in a common ancestor of Cercozoa and Euglenozoa (Cavalier-Smith, 1999), but the idea remains controversial as compelling sequence evidence is unavailable to rule out the alternative possibility that euglenoid and chlorarachnean plastids were separately implanted, as shown by the asterisks. Whether Apusozoa are really ancestrally heterotrophic and early divergent bikonts, as shown, is also uncertain. If instead they diverged after the green algal plastid entered the ancestral cabozoan (e.g. as sisters to excavates, see text), there might be no surviving ancestrally heterotrophic bikonts. As explained previously (Cavalier-Smith 2002b), I consider ciliary development in the biciliate unikont Physarum not to involve ciliary transformation homologous with that of bikonts.

2001; Silberman et al., 2002; Brugerolle et al., 2002): they are holophyletic on two (Cavalier-Smith, 2002b; Fig. 1)], their cenancestor must have been photosynthetic. In my view, the simplest interpretation of the origin of the trichozoan gnd gene is that it has a common origin with that of discicristates but has evolved so rapidly (like virtually all trichozoan genes) that decisive sequence evidence for this common origin has been lost.

I consider that the origin of all three enzymes discussed above is more simply explained by the cabozoan theory of secondary symbiogenesis, which I have recently revised in the light of new evidence from protein targeting and genome sequencing (Cavalier-Smith, 2003), rather than by three independent lateral gene transfers. One limitation in using the glucokinase and GPI gene transfers as arguments for the holophyly of Trichozoa is that, on the cabozoan theory, they must have entered the cabozoan chimaera prior to the divergence of Metamonada from Loukozoa and might also be present in some other cabozoan lineages, which are very poorly sampled for these genes or their enzymes. Trypanosomes are the only group currently with extensive genome/EST (expressed sequence tag) sequencing that might have detected them, but so far has not. However, any cladistic argument is limited by inadequate sampling 
and the possibility of secondary losses in related groups. Most available evidence is consistent with the view that Trichozoa are holophyletic. Because protein genes are so much less well sampled for Anaeromonadea, the evidence that Metamonada also are holophyletic is weaker, but cytologically reasonable.

\section{What were the ancestors of Metamonada?}

The similarities in ciliary roots between Carpediemonas and Malawimonas on the one hand and Carpediemonas and retortamonads on the other (Simpson \& Patterson, 1999, 2001) strongly suggest that the ancestral metamonad evolved from an aerobic loukozoan generally similar to Malawimonas in root structure, as well as in having vanes on the posterior cilium. Such an ancestor could have become the first metamonad by converting its mitochondria into hydrogenosomes and accelerating its ciliary development to make four cilia. This is consistent with the rRNA tree topology of Fig. 1, but neither tubulin nor chaperonin trees support a specific relationship of metamonads to Malawimonas (Edgcomb et al., 2001; Archibald et al., 2002).

\section{Age of Metamonada and Trichozoa}

We do not know whether the few free-living diplomonads (some Trepomonas and Hexamita), retortamonads (some Chilomastix: Bernard et al., 1997) and parabasalians (e.g. Ditrichomonas: Farmer, 1993) are ancestrally so or evolved secondarily from gut symbionts. The deep divergence on molecular trees between the purely endobiotic trichonymphids and the Trichomonadea and between the purely parasitic Giardiida and Distomatida/Retortamonadida is easiest to understand if both Parabasalia and Eopharyngia were ancestrally gut symbionts. The fact that free-living trichomonads seem to be a single derived clade nested among symbionts (Edgcomb et al., 1998) suggests that they escaped secondarily from guts. The fact that Trichozoa are so predominantly gut symbionts was always as awkward for the idea that they were really early-diverging eukaryotes as was their unusually high cytoskeletal complexity. If, as now seems clear, Metamonada are indeed relatively derived and advanced excavates, there is no longer any obstacle to the traditional view that oxymonads, Parabasalia and Eopharyngia evolved after the origin of the animal gut and that their morphological complexities were adaptations to this food-rich and relatively sheltered anaerobic habitat. The rapid evolutionary rates of their genes might also be a consequence of this. However, although the few free-living Parabasalia and Eopharyngia might be secondarily so, it is likely that Trimastix and Carpediemonas have always been free-living; thus, the ancestral metamonad anaerobiosis and tetrakonty could have evolved before animals.

Elsewhere, I argued that bikonts arose about 570 million years (My) ago and that the cabozoan symbiogenesis may have been roughly $530 \mathrm{My}$ ago (Cavalier-Smith, 2002b). However, the new evidence that Amoebozoa are sisters to opisthokonts rather than to bikonts means that the primary eukaryotic split is between unikonts and bikonts. Thus bikonts could be (but need not be) essentially as old as eukaryotes (i.e. almost $900 \mathrm{My}$ in round figures: CavalierSmith, 2002a). Therefore, the origin of chloroplasts could also be distinctly earlier than I suggested then (possibly closer to $\sim 800$ than to $\sim 600 \mathrm{My}$ ago), as could the later origin of green algae and the necessarily subsequent cabozoan symbiogenesis. An upper limit of 520 My would be a reasonable guess for the age of the basically gut commensal Eopharyngia, Parabasalia and oxymonads, by which time the bilaterian animal gut was in full fermentative swing (I here assume that the Cambrian explosion around $530 \mathrm{My}$ ago was caused by the origin of the anus and bilaterality). As Trichonymphea inhabit both termites and Cryptocercus, they may have originated in their common wood-eating ancestor. Thus, they have probably existed for at least 350 My (Gaunt \& Miles, 2002), and the separation of Parabasalia and Eopharyngia would be earlier. Very likely, the gut-commensal metamonad groups originated some time in the Cambrian, over $450 \mathrm{My}$ ago, but the range of uncertainty is considerable, and they could probably have originated any time in the period $\sim 520-360$ My ago. The origin of Trichozoa and, even more so, Metamonada must predate this, probably be at least a few score millions of years, to give the resolution seen on molecular trees. The fact that the branching position of the short-branch Trimastix compared with other bikonts is so hard to resolve on rRNA trees suggests that the Metamonada originated during the major bikont radiation, when the plant and chromist kingdoms were undergoing their own radiation, arguably in the late Neoproterozoic period, 570-535 My ago. I suggest that Metamonada may have originated about 600-530 My ago, that excavates may be 700-580 My old and that the cabozoan symbiogenesis may be 750-600 My old, in very round figures. This period was characterized by repeated global or near global glaciations (Hoffman et al., 1998) and interpretation of the microfossils, some probably eukaryotic algae, is still problematic (Knoll, 2000; Corsetti et al., 2003).

\section{What were the ancestors of Discicristata?}

Although O'Kelly (1993) suggested that the discoid cristae of Malawimonas might signify a relationship with discicristates, tubulin and chaperonin genes suggest that discicristates may be closer to the jakobids $R$. americana and J. libera (Edgcomb et al., 2001; Archibald et al., 2002). rRNA trees confirm that these 'core jakobids' are closely related to each other (Cavalier-Smith, 2000; Simpson et al., 2002a), whereas Jakoba incarcerata is distinctly more distant. They also suggest that jakobids are related to both discicristates and metamonads (Cavalier-Smith, 2002b), but somewhat more closely to the former (Fig. 1). Contrary to O'Kelly's suggestion, Malawimonas appears to be closer to Metamonada and jakobids to Discicristata (Fig. 1). As the flat cristae of Percolozoa are often less clearly discoid than those of Euglenozoa, their loukozoan common ancestor might also have had more generalized flattened 
cristae like J. libera or even tubular ones like Reclinomonas. It is likely that it was biciliate, and that the parallel centrioles of discicristates evolved before Euglenozoa and Percolozoa diverged. One scenario for such a change of orientation would be that it took place in a loricate histionid-like loukozoan similar to Reclinomonas. In these, the lorica prevents the anterior cilium from pointing forwards as sharply as in Jakoba.

Such a flagellate might even improve its feeding by making the two centrioles parallel and using the two cilia in a concerted pumping action like that of Percolomonas (Fenchel \& Patterson, 1986) to draw bacteria into the groove. Once this began, multiplication of the anterior cilia to allow all four to pump together, as in Percolomonas, could have initiated the quadriciliate state for Percolozoa and efficiency improved by losing the lorica and attaching temporarily to the substratum by the longer posterior cilium. On this scenario, the reclining state of Percolomonas on a substratum with no amoeboid phase could be an ancestral condition for all Percolozoa, and the amoeboid condition of Heterolobosea secondarily interpolated to become a novel trophic phase. Once the amoeba became the trophic phase and the ciliated one served primarily for dispersal, the posteriad direction of the centrioles was no longer needed for feeding and the kinetid became reorientated more towards the cell apex for more efficient swimming, but retained the parallel nature of the centrioles that evolved for the percolomonad type of feeding. Subsequently, some Heterolobosea (Vahlkampfia, Pseudovahlkampfia and the gruberellids) lost the ciliated stage altogether to become obligate amoebae. This scenario does not necessarily require that Percolomonas cosmopolitanus itself never had an amoeboid phase; molecular data are needed in order to establish whether it is ancestrally or secondarily without one.

Prior to the origin of the quadriciliate condition and the loss of Golgi stacking to form the cenancestral percolozoan, the hypothetical biciliate eodiscicristae intermediate took up a more active mode of feeding by gliding on or swimming close to surfaces and thereby evolved into the ancestral euglenozoan. Like the dispersal phase of the Heterolobosea, it reorientated its centrioles to the front to improve swimming, retaining their parallel nature, but curved the posterior cilium backwards to allow it to be used as a skid to hold the body close to the surface. Associated with these changes was the loss of the ventral groove and the origin of a type-I feeding apparatus (probably the ancestral type; Triemer \& Farmer, 1991) instead, to enable the ancestral euglenozoan to graze efficiently on the surface. This feeding apparatus is supported by the right microtubular band of the posterior centriole, which therefore could no longer be used to support the rim of a feeding groove at the same time.

If this is correct, the simplest way to allow this band to support the cytopharynx at the same time as allowing the cytostome to open on the underside facing the substratum and the anterior cilium to point forwards without changing the parallelism of the centrioles or the orientation of their connections to the posterior roots would be to introduce a sharply reflexed S-curve into the right root and to increase the proximal curvature of the left root. The reflexed curvature of the right root would necessarily push the two basal bodies towards the interior of the cell, thereby generating the characteristic and unique euglenoid ciliary pocket. Thus, the characteristic euglenoid ciliary pocket and reflexed right root are inevitable side-effects of the origin of the cytopharynx having occurred in the postulated biciliate ancestor with two originally posteriad cilia and a kinetid set back from the apex on the ventral surface (like Percolomonas) and with two parallel posteriad centrioles, rather than in an ancestor like Jakoba with a near apical anisokont kinetid.

As the most divergent euglenoids, the petalomonads, and also the ancestral kinetoplastids, the free-living bodonids, mostly feed this way and often have similar ingestion apparatuses, grazing on or close to surfaces was almost certainly the ancestral feeding niche for Euglenozoa: it still is the predominant one. Even photosynthetic euglenoids are not purely autotrophic, but haunt bacteria-rich surfaces with many bacteria generating acetate and vitamins (Walne \& Kivic, 1990). I suggest that the origin of the characteristic two dissimilar paraxonemal rods of Euglenozoa (Simpson, 1997) was to help hold the two cilia in a different orientation and to cause them to beat very differently to increase their ability to swim along the substratum. The associated hairs would help adhesion to the substratum. Basically, the rods and hairs, like the cytostome/ cytopharynx, were adaptations for surface grazing.

Unstudied and unnamed Loukozoa may still exist that are better models for intermediate stages postulated in the above scenarios: for example, Fenchel et al. (1995) depict an anaerobic flagellate species 2 with two posteriad cilia associated with a groove, quite similar to the postulated missing link between Loukozoa and Discicristata. A similar organism, but aerobic, would be a better model for the ancestor of discicristates than any named loukozoan species.

Although the precise branching order at the base of Euglenozoa is uncertain, there are some indications from gamma-corrected rRNA trees (e.g. Fig. 1) that euglenoids may be paraphyletic and that kinetoplastids and diplonemids may both be secondarily derived from them; Busse \& Preisfeld (2002) also find weak support for euglenoid holophyly. If this were so, the euglenoid proteinaceous strips may have evolved during the very origin of Euglenozoa at the time of, and have been instrumental in, the transformation of the feeding groove into a cytopharynx and have been lost by kinetoplastids and diplonemids. Each glycoprotein strip is subtended by microtubules nucleated by the dorsal microtubular root of the anterior cilium, quite similarly to Loukozoa. It is unclear whether bodonids never had these strips and extra microtubules or whether they lost them, possibly to allow efficient miniaturization coupled with maintaining sufficient flexibility to ingest 
numerous bacteria rapidly and thus to grow faster than if constricted by a rigid corset of strips.

\section{The sisters and ancestors of excavates}

According to the cabozoan theory, the common ancestor of Euglenozoa and Cercozoa was a biciliate photophagotroph, so the foregoing origin of Euglenozoa must have taken place in a photophagotroph. Although photosynthetic euglenoids have lost phagotrophy, the cercozoan chlorarachnean algae have mostly retained the ability to phagocytose bacteria and most are benthic. Very probably, the ancestral chlorarachneans were benthic (Ishida et al., 1999), as are most heterotrophic Cercozoa, making it likely that the cabozoan ancestor was a benthic photophagotroph. There is increasing evidence that Cercozoa and Retaria (Foraminifera and Radiolaria) are a clade designated 'core Rhizaria' (see Cavalier-Smith, 2003; Cavalier-Smith \& Chao, 2003b). Thus, on the cabozoan theory, all excavates, Cercozoa and Retaria are cabozoans; these taxa do form a clade on a recent rRNA tree (Cavalier-Smith, 2002a). Even in Fig. 1, where they are not a clade, the two groups are very close. The position of the two other phyla, Apusozoa (currently including only Thecomonadea: Cavalier-Smith, 2002b; Cavalier-Smith \& Chao, 2003b) and Heliozoa, which were placed in the Rhizaria (Cavalier-Smith, 2002b), is problematic. They may be mutually related (Cavalier-Smith \& Chao, 2003a), but Fig. 1 and most $18 \mathrm{~S}$ rRNA trees discussed earlier (Cavalier-Smith \& Chao, 2003a) weakly suggest that centrohelid heliozoa are closer to haptophytes than to core Rhizaria or Apusozoa. Fig. 2 therefore places centrohelids within Chromista, not Rhizaria.

Several rRNA trees weakly suggest that Thecomonadea may be the most divergent bikonts (Cavalier-Smith, 2000, 2002b; Cavalier-Smith \& Chao, 2003b), but Hsp90 trees place them weakly amongst other bikonts (Stechmann \& Cavalier-Smith, 2003a). Fig. 1 weakly groups Thecomonadea with Diphylleia and the aberrant putative amoebozoan 'Mastigamoeba invertens'. There is no morphological reason to suppose that the separation of ' $M$. invertens' from other Amoebozoa on this tree is correct; it does group with them on one published tree (Bolivar et al., 2001) and on some (but not most) of my unpublished trees. However, the grouping of Thecomonadea and Diphylleia is not implausible cytologically. Both groups are probably ancestrally bikont and have a ventral groove supported laterally at its rims only by microtubule bands; unlike Loukozoa in the present sense, both lack splayed out microtubules supporting its floor and ciliary vanes. I therefore move Diphyllatea from Loukozoa back to Apusozoa, where they were previously (Cavalier-Smith, 2000). A distant relationship of both Diphyllatea and Thecomonadea to Loukozoa, as suggested (Cavalier-Smith, 2002b) for Diphyllatea alone, cannot be ruled out by present single-gene trees, which have insufficient resolution. Because the position of both apusozoan classes (and their putative mutual relationship) is so uncertain, I exclude Apusozoa from both Excavata and Rhizaria here as Protozoa incertae sedis (Table 1). If
Apusozoa diverged prior to the divergence of Excavata and core Rhizaria, they are probably primitively heterotrophic. If, however, they are sisters to Excavata, as their groove, albeit differently supported cytoskeletally than in Loukozoa, weakly suggests, there would have been one more cabozoan plastid loss than with the topology shown in Fig. 2. In this case, the ancestral cabozoan evolved from an unknown early bikont with no known surviving ancestrally heterotrophic relatives. If, however, Apusozoa are not cabozoans, but ancestrally heterotrophic, they could occupy a key evolutionary position as the only primitively heterotrophic bikonts, and thus be valuable outgroups for understanding the origins of cabozoa, plants and chromalveolates.

\section{Envoi}

Although I have advocated treating Loukozoa, Metamonada and Percolozoa all as separate phyla, there is no doubt that the phenotypic disparity among them is less than that between them and Euglenozoa. However, I attribute their greater similarity in ciliary structure and roots (Simpson \& Patterson, 1999; Simpson et al., 2000) to shared ancestral characters that were lost when the ancestral euglenozoan became an active grazer with a cytopharynx as described above and lost the groove and evolved ciliary paraxonemal rods instead of vanes. Yet, even here, the separation of Euglenozoa may not be as marked as it first appears. Trimastix marina has a short cytopharynx at the far end of its groove supported by the right microtubular root, and the cytopharynxes of retortamonads and the percolozoan Tetramitus rostratus are similarly supported by right root microtubules, as is the euglenozoan type-I ingestion apparatus. Does this mean that the common ancestor of all these groups had a groove and a cytopharynx associated with the right root at its distal tip (and that all excavate cytopharynxes are strictly homologous, as I have sometimes conjectured: Cavalier-Smith, 1992)? Or is it that the loukozoan groove, its cytoskeleton and favoured spots for ingestion predispose these related cells to evolve in parallel a cytopharynx that is supported by the right rather than the left root?

The contrast between the euglenozoan paraxonemal rods and the vanes of the other three phyla may also not be really fundamental. Conceivably, some of their key skeletal proteins may be related. In Trimastix marina, the posterior cilium has a typical double vane, but the anterior one has an amorphous paraxonemal rod (Simpson et al., 2000); although this does not resemble the regular multilayer lattice of euglenozoan paraxonemal rods or the periodic structure of excavate vanes, it might be evolutionarily related to the former and developmentally related to the latter at the protein level. These possibilities emphasize that our judgement of degree of disparity should not be set in stone. Yet, they are useful in trying to decide where to put boundaries between major taxa in what was historically a continuum. 


\section{Revised diagnoses of taxa}

\section{Emended diagnosis of phylum Loukozoa Cavalier-Smith 1999}

Ancestrally and typically aerobic zooflagellates with tubular, flat or discoid mitochondrial cristae; cristae rarely absent (only Jakoba incarcerata). Golgi dictyosome beside the kinetid. Nucleus attached by fibres to the two apical or subapical sharply diverging centrioles as a biciliate karyomastigont and with two main posterior roots of partially splayed microtubular bands supporting the edges of a longitudinal feeding groove associated with the posterior cilium and a third singlet microtubule root lying between them. Left root supported internally by a multilayered, striated C-fibre with internal offset vanes between the layers. Right root supported ventrally by a double-leaved, crossstriated B-fibre originating from the junction between the left root and the posterior centriole. Posterior cilium with a single lateral flange or vane. Ciliary transition zone without an axial sleeve around the central pair (in contrast to Diphylleida). An anterior dorsal microtubular fan diverges from the kinetid.

\section{Diagnosis of Malawimonadea classis nov.}

Anisokont anaerobic biciliate zooflagellates with discoid mitochondrial cristae and a single ventral vane on the posterior cilium (Jakobea have a dorsal one instead) and two divergent centrioles. With curved, double-leaved I-fibre alongside anterior end of right root; the right root splits into a left and right half close to its origin. Left root supports only the left wall of the groove, unlike in jakobids, where it supports at least half the groove floor. With anterior microtubule band nucleating many of the fan microtubules. Mitochondrial cristae discoid.

Etymology: from the sole genus, Malawimonas (O'Kelly \& Nerad, 1999).

\section{Diagnosis of Malawimonadida ord. nov.}

Diagnosis as for class Malawimonadea.

\section{Diagnosis of Malawimonadidae fam. nov.}

Diagnosis as for class Malawimonadea.

\section{Emended diagnosis of phylum Metamonada Grassé 1952 stat. nov. Cavalier-Smith 1981}

Ancestrally anaerobic quadriciliate zooflagellates; with hydrogenosomes instead of mitochondria or without mitochondria or hydrogenosomes. Ancestrally with a nucleus attached by fibres to the four centrioles as a quadriciliate karyomastiont with a posterior cilium bearing two vanes (not just a single one as in Loukozoa and the percolozoan Psalteriomonas) and with two posterior microtubular roots associated with a feeding groove [the groove was later lost (Parabasalia) or converted to/supplemented by a cytopharynx
(Eopharyngia)]. With a strong evolutionary tendency to multiply karyomastigonts or sometimes secondarily to reduce the number of cilia. Golgi dictyosomes ancestrally present but independently suppressed in vegetative Eopharyngia and oxymonads.

\section{Emended diagnosis of class Anaeromonadea Cavalier-Smith 1996/7}

Quadriciliate anaerobic zooflagellates without cristate mitochondria; with or without hydrogenosomes and Golgi dictyosome. Ancestrally with anterior microtubule band nucleating many of the fan microtubules (unlike Jakobea, but like Malawimonadea). Golgi dictyosomes not attached to a striated parabasal filament.

\section{Diagnosis of Trimastigida ord. nov.}

Quadriciliate anaerobic zooflagellates with subapical, cruciately arranged centrioles, with anterior, posterior and two lateral cilia; posterior cilium with dorsal and ventral vane; hydrogenosome-like organelles.

Etymology: from the genus Trimastix (see Brugerolle \& Patterson, 1997; O’Kelly et al., 1999; Simpson et al., 2000).

\section{Emended diagnosis of subphylum Trichozoa Cavalier-Smith 1996/7}

Ancestrally with one posterior and three anterior cilia (the tetrakont arrangement), hydrogenosomes and Golgi dictyosomes, all secondarily lost in at least some groups; recurrent cilium with two or three ciliary vanes or smooth.

\section{Diagnosis of Trichonymphea classis nov.}

Huge cells with a complex rostrum terminated by a hyaline mobile cap separated from the rest of the cell by a joint. Numerous longitudinal rows of cilia extending from a bare apical region along all sides of the cell. Cell posterior bare of cilia and used for phagotrophy and sex. Chromosomes with centromeric attachments to the nuclear envelope visible in interphase. Obligate symbionts of termites and the wood-eating cockroach Cryptocercus.

Etymology: after the included genus Trichonympha.

\section{Diagnosis of Carpediemonadea classis nov.}

Biciliate zooflagellates with three centrioles; anaerobic with a hydrogenosome-like organelle. With curved, doubleleaved I-fibre alongside anterior end of right root; the right root splits into a left and right half close to its origin. Left root supports only the left wall of the groove, unlike in jakobids, where it supports at least half the groove floor. With anterior microtubule band nucleating many of the fan microtubules.

Etymology: after the sole genus, Carpediemonas (see Simpson \& Patterson, 1999). 


\section{Diagnosis of superclass 2. Carpediemonadia superclassis nov.}

Diagnosis as for class Carpediemonadea.

\section{Diagnosis of Carpediemonadida ord. nov.}

Diagnosis as for class Carpediemonadea.

\section{Diagnosis of Carpediemonadidae fam. nov.}

Diagnosis as for order Carpediemonadida.

\section{Emended diagnosis of superphylum Discicristata Cavalier-Smith 1993}

Flagellates or amoeboflagellates or amoebae typically with flat, usually discoid mitochondrial cristae. Ancestrally with two (Euglenozoa) or four (Percolozoa) subparallel centrioles bearing cilia and one anterior and two posterior microtubular roots.

\section{Emended diagnosis of phylum Percolozoa Cavalier-Smith 1991 emend. 2002}

Ancestrally aerobic quadriciliate zooflagellates with discoid mitochondrial cristae, sometimes secondarily anaerobic with hydrogenosomes instead of mitochondria. Ancestrally with a nucleus attached by fibres to the four parallel centrioles as a quadriciliate karyomastigont and with two posterior microtubular roots. Commonly alternate between a flagellate phase with a pellicle and a main trophic nonciliate amoeboid phase with eruptive lobose pseudopods; Golgi dictyosome absent. The karyomastigont is sometimes multiplied and, in amoeboid forms, the flagellate stage is sometimes absent. Kinetid rarely highly multiplied and reduced to a single centriole (Stephanopogon).

\section{Diagnosis of class 2. Percolatea classis nov.}

The new name Percolatea is preferred to either of the existing class names Percolomonadea and Pseudociliatea, since, if either were retained with broadened circumscription, it could cause confusion with the similarly named included order.

Flagellates with discoid mitochondrial cristae but no amoeboid phase; stacked Golgi dictyosomes absent; with single quadriciliate or numerous unikont kinetids.

Etymology: L. v. percolare to percolate, because Percolomonas is assumed to represent the ancestral phenotype and feeds by ciliary water currents.

The transfer of Stephanopogon to Cercozoa, once suggested because its centriolar cup resembles that of Spongomonas (Cavalier-Smith, 2002b), overweighted one character of unclear homology compared with the Golgi and mitochondrial characters responsible for originally including Stephanopogon in Percolozoa (Cavalier-Smith, 1991, 1993b); therefore, a recent revision of cercozoan higher classification excluded it from Cercozoa (Cavalier-Smith \& Chao, 2003b).

\section{Diagnosis of Diphyllatea classis nov.}

Zooflagellates with two (Diphylleia) or four (Collodictyon) anterior, equal-length, unvaned cilia with orthogonal centrioles linked by striated connectives. Deep ventral groove with rims supported by two broad, unsplayed microtubular centriolar roots with associated dense fibrous band, but cortical microtubules absent from the groove floor, unlike in Loukozoa. Ciliary transition region with a distal dense axial sleeve, a double-band axosome and indistinct proximal plate. Anterior microtubular root nucleates a dorsal microtubular fan. Sole order Diphylleida Cavalier-Smith 1993 and family Diphylleidae Cavalier-Smith 1993 (Diphylleia, Collodictyon).

Etymology: Gr. di- two; phyll- leaf, from the bilobed shape of the cells. The class name is not directly based on the generic name, as Diphylleia Michx. is unfortunately also the name of a flowering plant. Although Diphylla is a genus of vampire bats, Diphyllodes a bird of paradise, Diphyllidia a sea slug and Diphyllidea a group of tapeworms, none of these is sufficiently similar to cause confusion. Collodictyonidae Brugerolle 2002 is an invalid junior synonym for Diphylleidae, if Collodictyon is included in the same family as Diphylleia.

\section{ACKNOWLEDGEMENTS}

I thank NERC UK for research grants, the Canadian Institute for Advanced Research and NERC for fellowship support, D. Caron, R. Gast and A. P. Mylikov for gifts of cultures, T. Nerad and an anonymous referee for helpful advice, E. E. Chao for sequencing the jakobid genes, D. Spencer for identifying the intron and T. Richards for helpful discussion.

\section{REFERENCES}

Andersson, J. O. \& Roger, A. J. (2002). A cyanobacterial gene in nonphotosynthetic protists - an early chloroplast acquisition in eukaryotes? Curr Biol 12, 115-119.

Archibald, J. M., O'Kelly, C. J. \& Doolittle, W. F. (2002). The chaperonin genes of jakobid and jakobid-like flagellates: implications for eukaryotic evolution. Mol Biol Evol 19, 422-431.

Baldauf, S. L., Roger, A. J., Wenk-Siefert, I. \& Doolittle, W. F. (2000). A kingdom-level phylogeny of eukaryotes based on combined protein data. Science 290, 972-977.

Bapteste, E., Brinkmann, H., Lee, J. A. \& 8 other authors (2002). The analysis of 100 genes supports the grouping of three highly divergent amoebae: Dictyostelium, Entamoeba, and Mastigamoeba. Proc Natl Acad Sci U S A 99, 1414-1419.

Bernard, C., Simpson, A. G. B. \& Patterson, D. J. (1997). An ultrastructural study of a free-living retortamonad, Chilomastix cuspidata (Larsen \& Patterson, 1990) n. comb. (Retortamonadida, Protista). Eur J Protistol 33, 254-265.

Bolivar, I., Fahrni, J. F., Smirnov, A. \& Pawlowski, J. (2001). SSU rRNA-based phylogenetic position of the genera Amoeba and Chaos (Lobosea, Gymnamoebia): the origin of gymnamoebae revisited. Mol Biol Evol 18, 2306-2314.

Brugerolle, G. \& Müller, M. (2000). Amitochondriate flagellates. In The Flagellates, pp. 166-189. Edited by J. R. Green \& B. S. C. Leadbeater. London: Taylor \& Francis. 
Brugerolle, G. \& Patterson, D. J. (1997). Ultrastructure of Trimastix convexa Hollande, an amitochondriate anaerobic flagellate with a previously undescribed organization. Eur J Protistol 33, 121-130.

Brugerolle, G., Bricheux, G., Philippe, H. \& Coffe, G. (2002). Collodictyon triciliatum and Diphylleia rotans (=Aulacomonas submarina) form a new family of flagellates (Collodictyonidae) with tubular mitochondrial cristae that is phylogenetically distant from other flagellate groups. Protist 153, 59-70.

Busse, I. \& Preisfeld, A. (2002). Phylogenetic position of Rhynchopus sp. and Diplonema ambulator as indicated by analyses of euglenozoan small subunit ribosomal DNA. Gene 284, 83-91.

Cavalier-Smith, T. (1980). Cell compartmentation and the origin of eukaryote membranous organelles. In Endocytobiology: Endosymbiosis and Cell Biology, a Synthesis of Recent Research, pp. 893-916. Edited by W. Schwemmler \& H. E. A. Schenk. Berlin: de Gruyter.

Cavalier-Smith, T. (1981). Eukaryote kingdoms: seven or nine? Biosystems 14, 461-481.

Cavalier-Smith, T. (1982). The evolutionary origin and phylogeny of eukaryote flagella. In Prokaryotic and Eukaryotic Flagella: 35th Symposium of the Society of Experimental Biology, pp. 465-493. Edited by W. B. Amos \& J. G. Duckett. Cambridge: Cambridge University Press.

Cavalier-Smith, T. (1983). A 6-kingdom classification and a unified phylogeny. In Endocytobiology II, pp. 1027-1034. Edited by W. Schwemmler \& H. E. A. Schenk. Berlin: de Gruyter.

Cavalier-Smith, T. (1987a). The origin of eukaryotic and archaebacterial cells. Ann N Y Acad Sci 503, 17-54.

Cavalier-Smith, T. (1987b). The simultaneous symbiotic origin of mitochondria, chloroplasts, and microbodies. Ann N Y Acad Sci 503, 55-71.

Cavalier-Smith, T. (1987c). The origin of Fungi and pseudofungi. In Evolutionary Biology of the Fungi, Symposium of the British Mycological Society no. 13, pp. 339-353. Edited by A. D. M. Rayner, C. M. Brasier \& D. Moore. Cambridge: Cambridge University Press.

Cavalier-Smith, T. (1989). Systems of kingdoms. In McGraw-Hill Yearbook of Science and Technology 1989, pp. 175-179. Edited by S. P. Parker. New York: McGraw-Hill.

Cavalier-Smith, T. (1991). Cell diversification in heterotrophic flagellates. In The Biology of Free-Living Heterotrophic Flagellates, pp. 113-131. Edited by D. J. Patterson \& J. Larsen. Oxford: Clarendon Press.

Cavalier-Smith, T. (1992). Origin of the cytoskeleton. In The Origin and Evolution of the Cell, pp. 79-106. Edited by H. Hartman \& K. Matsuno. Singapore: World Scientific Publishers.

Cavalier-Smith, T. (1993a). Kingdom Protozoa and its 18 phyla. Microbiol Rev 57, 953-994.

Cavalier-Smith, T. (1993b). Percolozoa and the symbiotic origin of the metakaryote cell. In Endocytobiology V, pp. 399-406. Edited by H. Ishikawa, M. Ishida \& S. Sato. Tübingen: Tübingen University Press.

Cavalier-Smith, T. (1997). Amoeboflagellates and mitochondrial cristae in eukaryotic evolution: megasystematics of the new protozoan subkingdoms Eozoa and Neozoa. Arch Protistenkd 147, 237-258.

Cavalier-Smith, T. (1998). A revised six-kingdom system of life. Biol Rev Camb Philos Soc 73, 203-266.

Cavalier-Smith, T. (1999). Principles of protein and lipid targeting in secondary symbiogenesis: euglenoid, dinoflagellate, and sporozoan plastid origins and the eukaryote family tree. J Eukaryot Microbiol 46, 347-366.

Cavalier-Smith, T. (2000). Flagellate megaevolution: the basis for eukaryote diversification. In The Flagellates, pp. 361-390. Edited by J. R. Green \& B. S. C. Leadbeater. London: Taylor \& Francis.
Cavalier-Smith, T. (2002a). The neomuran origin of archaebacteria, the negibacterial root of the universal tree and bacterial megaclassification. Int J Syst Evol Microbiol 52, 7-76.

Cavalier-Smith, T. (2002b). The phagotrophic origin of eukaryotes and phylogenetic classification of Protozoa. Int J Syst Evol Microbiol 52, 297-354.

Cavalier-Smith, T. (2002c). Chloroplast evolution: secondary symbiogenesis and multiple losses. Curr Biol 12, R62-R64.

Cavalier-Smith, T. (2003). Genome reduction and evolution of novel genetic membranes and protein-targeting machinery in eukaryoteeukaryote chimaeras (meta-algae). Philos Trans R Soc Lond B Biol Sci 358, 109-133.

Cavalier-Smith, T. \& Chao, E. E. (1996). Molecular phylogeny of the free-living archezoan Trepomonas agilis and the nature of the first eukaryote. J Mol Evol 43, 551-562.

Cavalier-Smith, T. \& Chao, E. E.-Y. (2003a). Molecular phylogeny of centrohelid heliozoa, a novel lineage of bikont eukaryotes that arose by ciliary loss. J Mol Evol 56, 387-396.

Cavalier-Smith, T. \& Chao, E. E.-Y. (2003b). Phylogeny of Choanozoa, Apusozoa, and other protozoa and early eukaryote megaevolution. J Mol Evol 56, 540-563.

Cavalier-Smith, T. \& Chao, E. E.-Y. (2003c). Phylogeny and classification of phylum Cercozoa (Protozoa). Protist 154, 341-358.

Chatton, E. (1925). Pansporella perplexa, réflexions sur la biologie et la phylogenèse des Protozoaires. Ann Sci Nat Biol Anim Zool (10e sér) 8, 6-84 (in French).

Chatton, E. (1937). Gregarella fabrearum Chatt. et Brach., protiste parasite du cilié Fabrea salina. Arch Zoo Exp Géné 78, 216-237 (in French).

Corliss, J. O. (1985). The kingdom Protista and its 45 phyla. Biosystems 17, 87-126.

Corliss, J. O. (1994). An interim utilitarian ("user friendly") hierarchical classification and characterisation of the protists. Acto Protozool 33, 1-51.

Corsetti, F. A., Awramik, S. M. \& Pierce, D. (2003). A complex microbiota from snowball Earth times: microfossils from the Neoproterozoic Kingston Peak Formation, Death Valley, USA. Proc Natl Acad Sci U S A 100, 4399-4404.

Dacks, J. \& Roger, A. J. (1999). The first sexual lineage and the relevance of facultative sex. J Mol Evol 48, 779-783.

Dacks, J. B., Silberman, J. D., Simpson, A. G. B., Moriya, S., Kudo, T. Ohkuma, M. \& Redfield, R. J. (2001). Oxymonads are closely related to the excavate taxon Trimastix. Mol Biol Evol 18, 1034-1044.

Delwiche, C. F. (1999). Tracing the thread of plastid diversity through the tapestry of life. Am Nat 154 (Suppl. 4), S164-S177.

Diesing, K. M. (1865). Revision der Prothelminthen. Sitzungsber K Akad Wiss Wien, lii. Vienna: Vienna Academy of Sciences.

Diesing, K. M. (1866). Revision der Prothelminthen. Sitzungsber K Akad Wiss Wien, 1iii. Vienna: Vienna Academy of Sciences.

Dyall, S. D. \& Johnson, P. J. (2000). Origins of hydrogenosomes and mitochondria: evolution and organelle biogenesis. Curr Opin Microbiol 3, 404-411.

Edgcomb, V., Viscogliosi, E., Simpson, A. G. B., DelgadoViscogliosi, P., Roger, A. J. \& Sogin, M. L. (1998). New insights into the phylogeny of trichomonads inferred from small subunit rRNA sequences. Protist 149, 359-366.

Edgcomb, V. P., Roger, A. J., Simpson, A. G. B., Kysela, D. T. \& Sogin, M. L. (2001). Evolutionary relationships among "jakobid" flagellates as indicated by alpha- and beta-tubulin phylogenies. Mol Biol Evol 18, 514-522.

Embley, T. M. \& Hirt, R. P. (1998). Early branching eukaryotes? Curr Opin Genet Dev 8, 624-629. 
Farmer, M. A. (1993). Ultrastructure of Ditrichomonas honigbergii n. g., n. sp. (Parabasalia) and its relationship to amitochondrial protists. J Eukaryot Microbiol 40, 619-626.

Felsenstein, J. (1978). Cases in which parsimony or compatibility methods will be positively misleading. Syst Zool 27, 401-410.

Fenchel, T. \& Patterson, D. J. (1986). Percolomonas cosmopolitanus (Ruinen) n. gen., a new type of filter feeding flagellate from marine plankton. J Mar Biol Assoc U K 66, 465-482.

Fenchel, T., Bernard, C., Esteban, G., Finlay, B. J., Hansen, P. J. \& Iversen, N. (1995). Microbial diversity and activity in a Danish fjord with anoxic deep water. Ophelia 43, 45-100.

Flavin, M. \& Nerad, T. A. (1993). Reclinomonas americana n. g., n. sp., a new freshwater heterotrophic flagellate. J Eukaryot Microbiol 40, 172-179.

Gaunt, M. W. \& Miles, M. A. (2002). An insect molecular clock dates the origin of the insects and accords with palaeontological and biogeographic landmarks. Mol Biol Evol 19, 748-761.

Gerbod, D., Edgcomb, V. P., Noel, C., Zenner, L., Wintjens, R., Delgado-Viscogliosi, P., Holder, M. E., Sogin, M. L. \& Viscogliosi, E. (2001). Phylogenetic position of the trichomonad parasite of turkeys, Histomonas meleagridis (Smith) Tyzzer, inferred from small subunit rRNA sequence. J Eukaryot Microbiol 48, 498-504.

Gibbs, S. P. (1978). The chloroplasts of Euglena may have evolved from symbiotic green algae. Can J Bot 56, 2883-2889.

Grassé, P.-P. (1952). Classe des zooflagellés: Zooflagellata ou Zoomastigina (Euflagellata Claus 1887). Géneralités. In Traité de Zoologie, vol. 1, fasc. 1, pp. 574-578. Edited by P.-P. Grassé. Paris: Masson (in French).

Henze, K., Horner, D. S., Suguri, S., Moore, D. V., Sanchez, L. B., Müller, M. \& Embley, T. M. (2001). Unique phylogenetic relationships of glucokinase and glucosephosphate isomerase of the amitochondriate eukaryotes Giardia intestinalis, Spironucleus barkhanus and Trichomonas vaginalis. Gene 281, 123-131.

Hoffman, P. F., Kaufman, A. J., Halverson, G. P. \& Schrag, D. P. (1998). A Neoproterozoic snowball earth. Science 281, 1342-1346.

Honigberg, B. M. (1973). Remarks upon trichomonad affinities of certain parasitic protozoa. In Progress in Protozoology: Abstracts of Papers Read at the 4th International Congress of Protozoology, Clermont-Ferrand, 2-10 September 1973, p. 187. Edited by P. De Puytorac \& J. Grain. Clermont-Ferrand: Université de Clermont.

Honigberg, B. M., Balamuth, W., Bovee, E. C. \& 8 other authors (1964). A revised classification of phylum Protozoa. J Protozool 11, 7-20.

Horner, D. S. \& Embley, T. M. (2001). Chaperonin 60 phylogeny provides further evidence for secondary loss of mitochondria among putative early-branching eukaryotes. Mol Biol Evol 18, 1970-1975.

Ishida, K., Green, B. R. \& Cavalier-Smith, T. (1999). Diversification of a chimaeric algal group, the chlorarachniophytes: phylogeny of nuclear and nucleomorph small-subunit rRNA genes. Mol Biol Evol 16, 321-331.

Keeling, P. J. \& Doolittle, W. F. (1997). Evidence that eukaryotic triosephosphate isomerase is of alpha-proteobacterial origin. Proc Natl Acad Sci U S A 94, 1270-1275.

Kirby, H. (1947). Flagellates and host relationships of trichomonad flagellates. J Parasitol 33, 214-228.

Knoll, A. H. (2000). Learning to tell Neoproterozoic time. Precambrian Res 100, 3-20.

Lang, B. F., O’Kelly, C., Nerad, T., Gray, M. W. \& Burger, G. (2002). The closest unicellular relatives of animals. Curr Biol 12, $1773-1778$.
Leipe, D. D., Gunderson, J. H., Nerad, T. A. \& Sogin, M. L. (1993). Small subunit ribosomal RNA of Hexamita inflata and the quest for the first branch in the eukaryotic tree. Mol Biochem Parasitol 59, $41-48$.

Levine, N. D., Corliss, J. O., \& Cox, F. E. \& 13 other authors (1980). A newly revised classification of the protozoa. J Protozool 27, 37-58.

Moestrup, Ø. (2000). The flagellate cytoskeleton. In The Flagellates: Unity, Diversity and Evolution, pp. 69-94. The Systematics Association Special Volume Series 59. Edited by B. S. C. Leadbeater \& J. C. Green. London: Taylor \& Francis.

Moriya, S., Dacks, J. B., Takagi, A., Noda, S., Ohkuma, M., Doolittle, W. F. \& Kudo, T. (2003). Molecular phylogeny of three oxymonad genera: Pyrsonympha, Dinenympha and Oxymonas. J Eukaryot Microbiol 50, 190-197.

Morrison, H. G., Roger, A. J., Nystul, T. G., Gillin, F. D. \& Sogin, M. L. (2001). Giardia lamblia expresses a proteobacterial-like DnaK homolog. Mol Biol Evol 18, 530-541.

O'Kelly, C. (1993). The jakobid flagellates: structural features of Jakoba, Reclinomonas and Histiona and implications for the early diversification of eukaryotes. J Eukaryot Microbiol 40, 627-636.

O'Kelly, C. J. \& Nerad, T. A. (1999). Malawimonas jakobiformis n. gen., n. sp. (Malawimonadidae fam. nov.): a Jakoba-like heterotrophic nanoflagellate with discoidal mitochondrial cristae. J Eukaryot Microbiol 46, 522-531.

O'Kelly, C. J., Farmer, M. A. \& Nerad, T. A. (1999). Ultrastructure of Trimastix pyriformis (Klebs) Bernard et al:: similarities of Trimastix species with retortamonad and jakobid flagellates. Protist 150, 149-162.

Page, F. C. \& Blanton, R. L. (1985). The Heterolobosea (Sarcodina: Rhizopoda), a new class uniting the Schizopyrenida and the Acrasidae (Acrasida). Protistologica 21, 121-132.

Patterson, D. J. (1988). The evolution of protozoa. Mem Inst Oswaldo Cruz 83 (Suppl. 1), 580-600.

Patterson, D. J. (1999). The diversity of eukaryotes. Am Nat 154 (Suppl. 4), S96-S124.

Philippe, H. \& Adoutte, A. (1996). How reliable is our current view of eukaryotic phylogeny? In Protistological Actualities, pp. 17-33. Edited by G. Brugerolle \& J.-P. Mignot. Clermont-Ferrand: Université Blaise Pascal de Clermont Ferrand.

Philippe, H. \& Adoutte, A. (1998). The molecular phylogeny of Eukaryota: solid facts and uncertainties. In Evolutionary Relationships Among Protozoa, pp. 25-56. Edited by G. H. Coombs, K. Vickerman, M. A. Sleigh \& A. Warren. London: Kluwer.

Philippe, H., Lopez, P., Brinkmann, H., Budin, K., Germot, A., Laurent, J., Moreira, D., Muller, M. \& Le Guyader, H. (2000). Earlybranching or fast-evolving eukaryotes? An answer based on slowly evolving positions. Proc R Soc Lond B Biol Sci 267, 1213-1221.

Roger, A. J. (1999). Reconstructing early events in eukaryotic evolution. Am Nat 154 (Suppl. 4), S146-S163.

Roger, A. J., Svard, S. G., Tovar, J., Graham Clark, C., Smith, M. W., Gillin, F. D. \& Sogin, M. L. (1998). A mitochondrial-like chaperonin 60 gene in Giardia lamblia: evidence that diplomonads once harbored an endosymbiont related to the progenitor of mitochondria. Proc Natl Acad Sci U S A 95, 229-234.

Silberman, J. D., Simpson, A. G. B., Kulda, J., Cepicka, I., Hampl, V., Johnson, P. J. \& Roger, A. J. (2002). Retortamonad flagellates are closely related to diplomonads - implications for the history of mitochondrial function in eukaryote evolution. Mol Biol Evol 19, 777-786.

Simpson, A. G. B. (1997). The identity and composition of the Euglenozoa. Arch Protistenkd 148, 318-328. 
Simpson, A. G. B. \& Patterson, D. J. (1999). The ultrastructure of Carpediemonas membranifera (Eukaryota) with reference to the "excavate hypothesis". Eur J Protistol 35, 353-370.

Simpson, A. G. B. \& Patterson, D. J. (2001). On core jakobids and excavate taxa: the ultrastructure of Jakoba incarcerata. J Eukaryot Microbiol 48, 480-492.

Simpson, A. G. B., Bernard, C. \& Patterson, D. J. (2000). The ultrastructure of Trimastix marina Kent, 1880 (Eukaryota), an excavate flagellate. Eur J Protistol 36, 229-251.

Simpson, A. G. B., Roger, A. J., Silberman, J. D., Leipe, D. D., Edgcomb, V. P., Jermiin, L. S., Patterson, D. J. \& Sogin, M. L. (2002a). Evolutionary history of "early-diverging" eukaryotes: the excavate taxon Carpediemonas is a close relative of Giardia. Mol Biol Evol 19, 1782-1791.

Simpson, A. G. B., Radek, R., Dacks, J. B. \& O’Kelly, C. J. (2002b). How oxymonads lost their groove: an ultrastructural comparison of Monocercomonoides and excavate taxa. J Eukaryot Microbiol 49, 239-248.

Sleigh, M. A. \& Patterson, D. J. (1984). Protozoa. In A Synoptic Classification of Living Organisms. Edited by R. S. K. Barnes. Oxford: Blackwell Scientific.

Stechmann, A. \& Cavalier-Smith, T. (2002). Rooting the eukaryote tree by using a derived gene fusion. Science 297, 89-91.

Stechmann, A. \& Cavalier-Smith, T. (2003a). Phylogenetic analysis of eukaryotes using heat-shock protein Hsp90. J Mol Evol 57, 408-419.
Stechmann, A. \& Cavalier-Smith, T. (2003b). The root of the eukaryote tree pinpointed. Curr Biol 13, R665-R666.

Tachezy, J., Sanchez, L. B. \& Müller, M. (2001). Mitochondrial type iron-sulfur cluster assembly in the amitochondriate eukaryotes Trichomonas vaginalis and Giardia intestinalis, as indicated by the phylogeny of IscS. Mol Biol Evol 18, 1919-1928.

Triemer, R. E. \& Farmer, M. A. (1991). The ultrastructural organization of heterotrophic euglenids and its evolutionary implications. In The Biology of Free-Living Heterotrophic Flagellates, pp. 185-204. Edited by D. J. Patterson \& J. Larsen. Oxford: Clarendon Press.

van der Giezen, M., Slotboom, D. J., Horner, D. S., Dyal, P. L., Harding, M., Xue, G. P., Embley, T. M. \& Kunji, E. R. (2002). Conserved properties of hydrogenosomal and mitochondrial ADP/ ATP carriers: a common origin for both organelles. EMBO J 21, 572-579.

Walne, P. L. \& Kivic, P. A. (1990). Phylum Euglenida. In Handbook of Protoctista, pp. 270-287. Edited by L. Margulis, J. O. Corliss, M. Melkonian \& D. Chapman, Boston: Jones \& Bartlett.

Wolfe, M., Buchheim, M., Hegewald, E., Krienitz, L. \& Hepperle, D. (2002). Phylogenetic position of the Sphaeropleaceae (Chlorophyta). Plant Syst Evol 230, 161-171.

Wu, G., Henze, K. \& Müller, M. (2001). Evolutionary relationships of the glucokinase from the amitochondriate protist, Trichomonas vaginalis. Gene 264, 265-271. 